\title{
THE EFFECTS OF RAINFALL ON CARBON ISOTOPES OF POC IN THE TESHIO RIVER, NORTHERN JAPAN
}

\author{
Takafumi Aramaki ${ }^{1,2} \cdot$ Seiya Nagao $^{3} \cdot$ Yo-hei Nakamura $^{4} \cdot$ Masao Uchida $^{5} \cdot$ Yasuyuki Shibata $^{5}$ \\ ABSTRACT. During a rainfall event in early September 2006, the transport behavior of particulate organic carbon (POC) in \\ a small river (Teshio River, northern Japan) with alluvial plain and forest characteristics was investigated chiefly with carbon \\ isotopes. The radiocarbon $\left(\Delta^{14} \mathrm{C}\right.$ value $)$ of POC varied widely from $-56 \%$ at the beginning of the rain event to $-10 \%$ at peak \\ rainfall. The $\Delta^{14} \mathrm{C}$ values have a positive correlation with $\mathrm{C} / \mathrm{N}$ ratios and a negative correlation with $\delta^{13} \mathrm{C}$ values except for \\ the data from when both turbidity and water level were at their maximums due to rainfall. These results indicate that the \\ sources of organic matter in the river come from the surface layer of soil as the water level rises during a rainfall event.
}

\section{INTRODUCTION}

Knowing the organic carbon dynamics in river basins is required when studying the role of rivers in global biogeochemical cycles and organic carbon flux. Global riverine discharge of dissolved and particulate terrestrial matter is a substantial source of organic carbon in the ocean (Meybeck 1993; Hedges et al. 1997). In particular, small rivers in alluvial plain and forest areas have been recognized as a significant source of terrestrial sediment in the ocean (Milliman and Syvitski 1992). During rainfall events, a large amount of suspended solids washes out from river basins to coastal regions, so it is expected that a large amount of organic matter and nutrients is also carried to coastal regions. However, the amount and nature of the organic matter are strongly influenced not only by the watershed environment, including the regional vegetation and climate (Hedges 1992), but also the scale of the rainfall event. Thus, the transport behavior of organic matter in small rivers near alluvial plain and forest areas is still not entirely clear.

Stable carbon isotopes and radiocarbon of particulate organic carbon (POC) are useful tracers of the sources and behavior of POC in river systems (Masiello and Druffel 2001; Raymond and Bauer 2001; Nagao et al. 2005). They are also useful for investigating biogeochemical processes occurring in the soil (Trumbore and Harden 1997; Koarashi et al. 2005) because riverine organic matter is generally derived more from soil and plant material and less from phytoplankton (Meybeck 1982). Though past studies using ${ }^{14} \mathrm{C}$ analysis reported that the age of POC varied with the variation of water discharge by rainfall events (Masiello and Druffel 2001), observations chiefly with carbon isotopes on the nature variation of $\mathrm{POC}$ in small rivers with alluvial plain and forest during a rainfall event had rarely been performed. Therefore, as the first step, we intended to use carbon isotopic signatures such as $\Delta^{14} \mathrm{C}$ and $\delta^{13} \mathrm{C}$ values to investigate the transport and behavior of POC before and after rainfall in the Teshio River in northern Japan.

\footnotetext{
${ }^{1}$ Environmental Chemistry Division, National Institute for Environmental Studies, 16-2, Onogawa, Tsukuba, Ibaraki 3058506, Japan.

${ }^{2}$ Corresponding author. Email: ara@nies.go.jp.

${ }^{3}$ Low Level Radioactivity Laboratory, KU-INET, Kanazawa University, Wake, Nomi, Ishikawa 923-1224, Japan.

${ }^{4}$ Faculty of Environmental Earth Science, Hokkaido University, N5W10, Kita-ku, Sapporo 060-0810, Japan.

${ }^{5}$ AMS Facility (NIES-TERRA), National Institute for Environmental Studies, 16-2, Onogawa, Tsukuba, Ibaraki 305-8506, Japan.
}

(C) 2010 by the Arizona Board of Regents on behalf of the University of Arizona Proceedings of the 20th International Radiocarbon Conference, edited by A J T Jull RADIOCARBON, Vol 52, Nr 2-3, 2010, p 808-814 


\section{MATERIALS AND METHODS}

\section{Study Area}

The Teshio River is located in the northern part of Hokkaido Island, northern Japan, and runs into the Japan Sea through a narrow strip of lowland (Figure 1). The river has low turbidity except during the spring snowmelt period. The $256-\mathrm{km}$-long river has a watershed of $5590 \mathrm{~km}^{2}$; it originates at Mt Teshio-dake $(1558 \mathrm{~m})$ in the Kitami Mountains located in the northern part of Hokkaido Island. Land use of the Teshio River basin is $70 \%$ forest area with brown forest soil, $16 \%$ agricultural land, $1 \%$ urban area, and $13 \%$ other (Ileva et al. 2009). Major agricultural lands including paddy fields are located at the floodplain near the river, especially in the middle of the basin. Peat soil is distributed at the riparian floodplain in the lower basin. Geological features of the plain are mainly volcanic rocks with unconsolidated sediments. The slope of the riverbed from the headstream to the junction with the Nayoro River is more than 1/700. Mean annual precipitation during the $19 \mathrm{yr}$ from 1990 to 2008 is recorded as $992 \mathrm{~mm}$ at the Nayoro observatory, which is located near our sampling site (Japan Meteorological Agency 2009). The Teshio River's water discharge in 2006 was $28-240 \mathrm{~m}^{3} /$ $\mathrm{s}$ recorded at a water flow monitoring station at the Nayoro-Ohashi (Ministry of Land, Infrastructure, and Transport 2009).

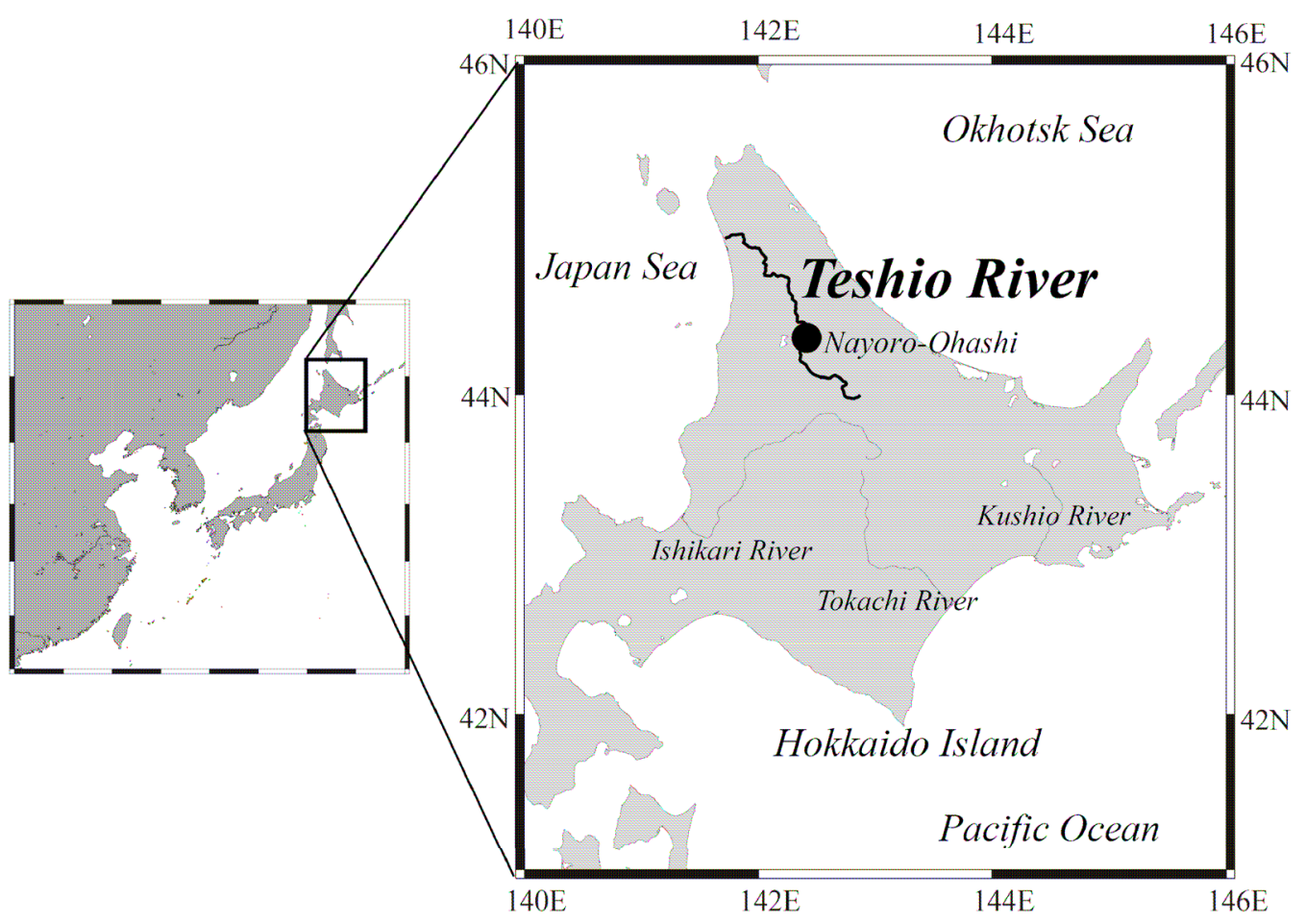

Figure 1 Sampling location (Nayoro-Ohashi) used in this study

\section{Sampling}

Water sampling was carried out during 4-6 September 2006 at a fixed point, Nayoro-Ohashi, located in the middle part of the Teshio River (Figure 1). Figure 2 shows the variations in precipitation, water discharge, and water level at Nayoro-Ohashi in early September 2006. During the obser- 
vation period, rain began during the night of 4 September and cleared up during the night of 5 September. The water discharge and water levels were at their maximum points during the night of 5 September. Thus, we collected 4 water samples: 1) the evening of 4 September as a sample before rainfall; 2) the morning of 5 September as a sample when precipitation was at its maximum; 3 ) the evening of 5 September as a sample when water discharge was at its maximum; and 4) the morning of 6 September as a sample after the rainfall. In this study, these sampling points were named as follows: 1) pre-event; 2) max precipitation; 3) max water discharge; and 4) post-event, respectively.



Figure 2 Variations of precipitation, water discharge, and water level at Nayoro-Ohashi in the Teshio River in early September 2006, including during our observation period. Arrows indicate time and date of river water sampling. 
Surface waters of about $100 \mathrm{~L}$ at the center of the flow were collected by bucket sampling from the Nayoro Bridge and then transferred to the laboratory in polyethylene containers. Suspended solid samples were concentrated from 28 to $59 \mathrm{~L}$ of water using a single-bowl continuous-flow centrifuge technique with a flow rate of $15 \mathrm{~L} / \mathrm{hr}$ (Nagano et al. 2003). The inside temperature of the centrifuge was maintained at $15-20^{\circ} \mathrm{C}$ to avoid transformation of solids (Nagao et al. 2005), and these solid samples were freeze-dried.

\section{Analyses}

Turbidity (the degree of opacity of water) is expressed in NTU units measured during water sampling using a water quality checker (U-21XD, Horiba Ltd, Japan). Suspended solid concentrations in river water were calculated by dividing the dried sample solid weights by the volume of centrifuged sample water.

POC contents of suspended solids were determined using a total organic carbon analyzer (WR-112, LECO Corporation, USA) and an elemental analyzer (NA1500, Fisons Instruments, Italy). Total nitrogen (TN) contents of suspended solids were also measured using the elemental analyzer. Prior to analysis, inorganic carbonate in a suspended solid sample was removed by adding $0.1 \mathrm{M} \mathrm{HCl}$. After the $\mathrm{HCl}$ mixed solution was left to stand for a night, it was placed in a centrifuge at $3000 \mathrm{rpm}$ and its clear supernatant liquid was discarded. The deposition was then rinsed by Milli- $\mathrm{Q}^{\mathrm{TM}}$ water, treated again in a centrifuge at $3000 \mathrm{rpm}$, and its clear supernatant liquid was discarded. Finally, we got a powder sample for POC and TN measurement by freeze-drying the deposition.

${ }^{14} \mathrm{C}$ measurement of $\mathrm{POC}$ in a powder sample, which was derived in the same way as the chemical treatment for POC and TN measurement, was performed by an accelerator mass spectrometer (AMS, Model 15SDH-2, National Electrostatics Corporation, USA) at the National Institute for Environmental Studies, Japan (Kume et al. 1997). The powder sample, adjusted to a weight of approximately $2 \mathrm{mg} \mathrm{C}$, was first converted to $\mathrm{CO}_{2}$ by combustion with $\mathrm{CuO}$ and $\mathrm{Ag}$ foil, then purified cryogenically. Next, the $\mathrm{CO}_{2}$ was reduced to graphite with $\mathrm{H}_{2}$ over $\mathrm{Fe}$ powder (Kitagawa et al. 1993). Its ${ }^{14} \mathrm{C} /{ }^{12} \mathrm{C}$ and ${ }^{13} \mathrm{C} /{ }^{12} \mathrm{C}$ ratios were measured using an AMS system. The ${ }^{14} \mathrm{C}$ activities were determined with respect to the international standard of oxalic acid (SRM-4990C, NIST, USA), and reported in $\Delta{ }^{14} \mathrm{C}$ (Stuiver and Polach 1977). The typical analytical error of $\Delta{ }^{14} \mathrm{C}$ was about $\pm 5 \%$ as a $1-\sigma$ value of the counting statistics. The difference between duplicate samples was less than the counting error. In addition, the ${ }^{14} \mathrm{C}$ background of a chemistry blank on our AMS measurement was given by the IAEA standard code $\mathrm{C}-1$, and its ${ }^{14} \mathrm{C} /{ }^{12} \mathrm{C}$ ratio was less than $1 \times 10^{-15}$.

Stable carbon isotope $\left({ }^{13} \mathrm{C}\right)$ measurement of POC in a powder sample, which was derived in the same way of chemical treatment for POC and TN measurement, was performed by an elemental analyzer (FLASH EA1112, Thermo Fisher Scientific Inc., USA) connected to a mass spectrometer (DELTA V Plus, Thermo Fisher Scientific Inc., USA). Its ${ }^{13} \mathrm{C} /{ }^{12} \mathrm{C}$ ratio is reported relative to the VPDB standard in $\delta^{13} \mathrm{C}(\%)$ units. The precision of measurement was $\pm 0.05 \%$ for the $\delta^{13} \mathrm{C}$ value.

\section{RESULTS AND DISCUSSION}

Turbidity, suspended solid concentration of water samples, POC weight percentages (wt $\%$ ), C/N molar ratios, $\Delta^{14} \mathrm{C}$, and $\delta^{13} \mathrm{C}$ values of suspended solid samples are presented in Table 1. During the rainfall event, the POC wt\% clearly decreased with increasing turbidity. The phenomenon has been reported for rivers worldwide (e.g. Paolini 1995; Gupta et al. 1997; Moreira-Turcq et al. 2003), and is explained by the fact that terrestrial plant debris is diluted by minerals and clays, and/or planktonic organic carbon is diluted by mineral sources from land (Meybeck 1982). However, the POC $\mathrm{wt} \%$ for the Teshio River is quite high, even after the decrease, as compared to the correlation 
between the total suspended solid and the POC wt $\%$ on major world rivers (Ittekkot 1988). This may mean that the organic-rich soil contributes to increases in suspended solids in the Teshio River by rainfall as well as organic-free particles by riverbed and/or riverbank erosion.

Table 1 Turbidity, suspended solid concentration of water samples, POC weight percentages, C/N ratios, $\Delta^{14} \mathrm{C}$, and $\delta^{13} \mathrm{C}$ values of suspended solid samples in Teshio River waters during the rainfall event in early September 2006.

\begin{tabular}{lrlllllll}
\hline $\begin{array}{l}\text { Sampling } \\
\text { date }\end{array}$ & \multicolumn{1}{c}{ Time } & $\begin{array}{l}\text { Turbidity } \\
\text { (NTU) }\end{array}$ & $\begin{array}{l}\text { Suspended solid } \\
(\mathrm{mg} / \mathrm{L})\end{array}$ & $\begin{array}{l}\text { POC } \\
(\mathrm{mg} / \mathrm{L})\end{array}$ & $\begin{array}{l}\text { POC } \\
(\mathrm{wt} \%)\end{array}$ & $\begin{array}{l}\mathrm{C} / \mathrm{N} \\
(\text { mole ratio) }\end{array}$ & $\begin{array}{l}\Delta^{14} \mathrm{C} \\
(\%)\end{array}$ & $\begin{array}{l}\delta^{13} \mathrm{C} \\
(\%)\end{array}$ \\
\hline 4-Sep-06 & $17: 30$ & 2.4 & 2.0 & 0.137 & 6.83 & 8.0 & -56.25 & -25.3 \\
5-Sep-06 & $9: 30$ & 54.0 & 46.3 & 2.62 & 5.65 & 9.7 & -38.11 & -26.6 \\
5-Sep-06 & $17: 10$ & 78.2 & 77.7 & 3.03 & 3.90 & 9.6 & -10.24 & -26.3 \\
6-Sep-06 & $9: 30$ & 38.0 & 26.1 & 1.09 & 4.16 & 8.7 & -50.77 & -26.5 \\
\hline
\end{tabular}

$\Delta{ }^{14} \mathrm{C}$ values varied widely from $-56 \%$ before the rain to $-10 \%$ when water discharge was at its maximum in response to the rainfall event. The relationship between the turbidity of river water and the $\Delta^{14} \mathrm{C}$ value of riverine POC is shown in Figure 3. The $\Delta{ }^{14} \mathrm{C}$ values exponentially increased with an increase in turbidity. As high turbidity results from an increase in water level and/or water discharge with rainfall (see Figure 2 and Table 1), the results suggest that the POC having relatively high $\Delta{ }^{14} \mathrm{C}$ value were carried into the river by rainfall. This may indicate that surface soil organic matter is carried into the rising river by rainfall, because the ${ }^{14} \mathrm{C}$ in soil organic matter usually decreases with depth (Trumbore 2000; Koarashi et al. 2005; Liu et al. 2006). In contrast, Masiello and Druffel (2001) reported that the $\Delta^{14} \mathrm{C}$ value of POC in the Santa Clara River in southern California, USA, decreased with an increase of water discharge in the river. This is because the Santa Clara River, which is mountainous river, drains a watershed underlain by marine shale, and $\Delta^{14} \mathrm{C}$ of POC having origin in minerals is sufficiently low. Furthermore, they observed the estuary of the river, and the water discharge difference between the high and low flow of the river was considerably larger than in our study, in which the water level rose less than $60 \mathrm{~cm}$ before and after rainfall (Figure 2). Thus, the discrepancy with our result arises from the situation of water discharge, climate, and regional vegetation in the watershed environment.

The relationships between $\Delta^{14} \mathrm{C}$ value of $\mathrm{POC}, \mathrm{C} / \mathrm{N}$ ratios of suspended solids, and $\delta^{13} \mathrm{C}$ value of $\mathrm{POC}$ are shown in Figure 4. The $\Delta^{14} \mathrm{C}$ values of POC are closely correlated with $\mathrm{C} / \mathrm{N}$ ratios and $\delta^{13} \mathrm{C}$ values, except for the data of maximum of water discharge. These results may also suggest that suspended solids with properties that were different from normal conditions were carried into the river by the rise of the river during rainfall. The $\mathrm{C} / \mathrm{N}$ ratios also had good positive correlation with turbidity (Table 1). In general, the $\mathrm{C} / \mathrm{N}$ ratio of soil is highest at the surface layer due to plants having a high $\mathrm{C} / \mathrm{N}$ ratio ( $>25$; Koarashi et al. 2005), and becomes low with depth due to decomposition of the organic matter by microbes (Koarashi et al. 2005). Thus, the results for the Teshio River indicate that surface soil was discharged into the river by the rise of the water level. Moreover, as shown in Figure $4 \mathrm{~b}$, the $\delta^{13} \mathrm{C}$ values of POC are plotted around $-26.5 \%$ except for the data of the pre-event. The $\delta^{13} \mathrm{C}$ values of POC after rainfall are $1 \%$ lower (lighter) than those found during normal conditions. As it was reported that the depth profile of $\delta^{13} \mathrm{C}$ values in soil organic matter become higher (more heavy) with depth because of decomposition by microbes (Koarashi et al. 2005; Liu et al. 2006), this trend also indicates an inflow of surface soil organic matter to the river by rainfall. Thus, we conclude that the tendency of $\Delta^{14} \mathrm{C}$ values of POC to increase during a rainfall event results from changes in the sources of soil organic matter to the river with the rising of the water level. 


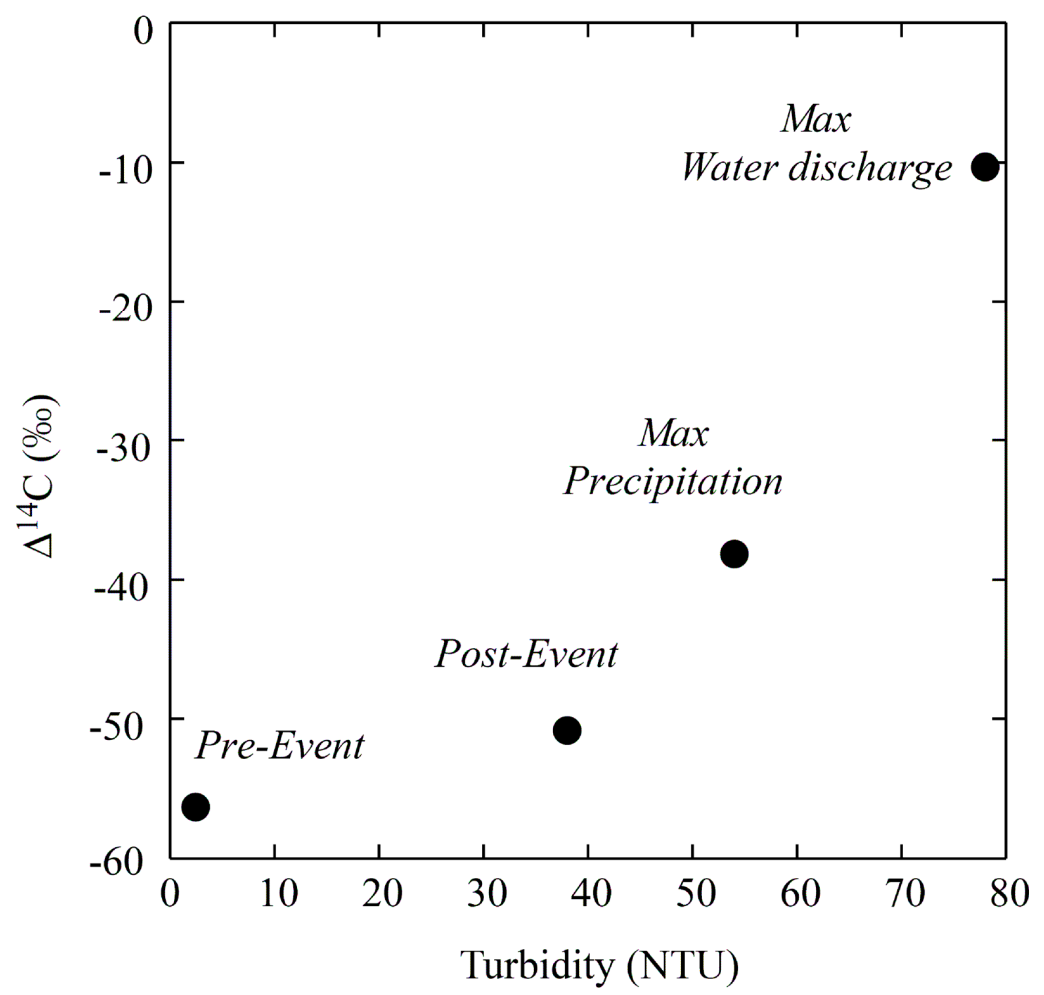

Figure 3 Relationship between turbidity of river water and $\Delta{ }^{14} \mathrm{C}$ value of riverine POC
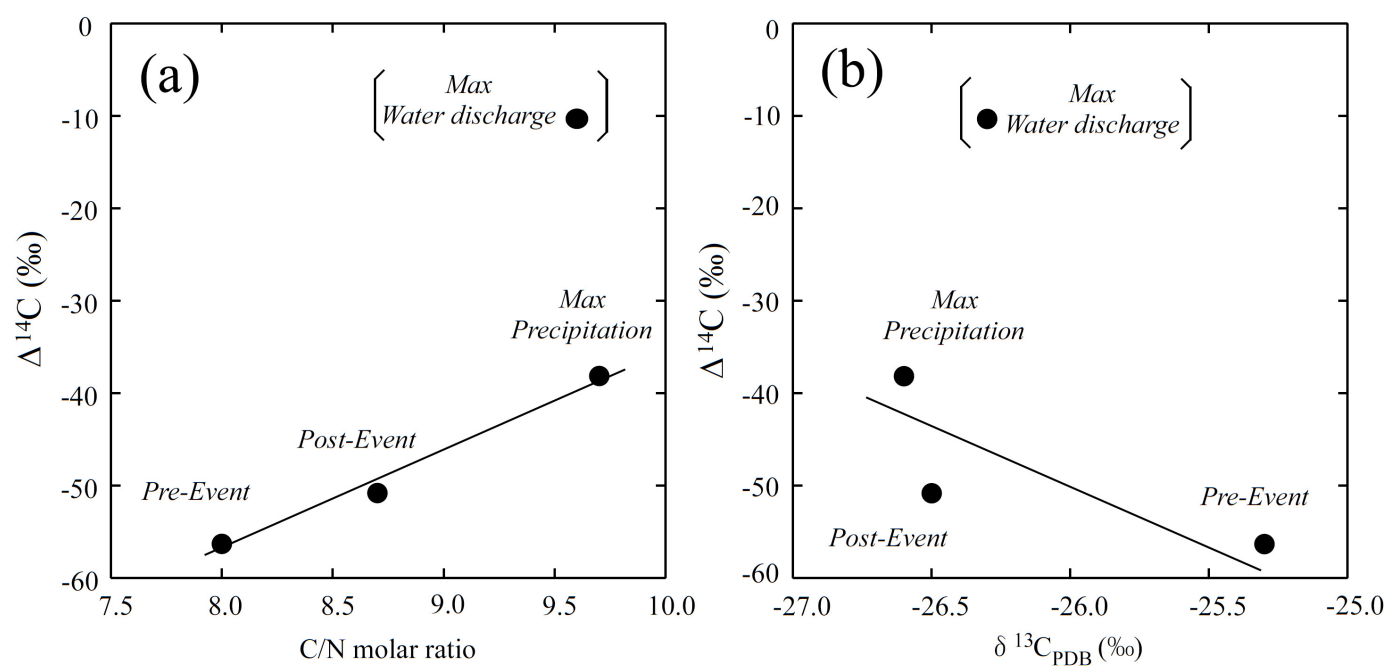

Figure 4 Relationship between $\Delta^{14} \mathrm{C}$ value of riverine $\mathrm{POC}$ and $\mathrm{C} / \mathrm{N}$ molar ratio of suspended solids in the river water (a) and between $\Delta^{14} \mathrm{C}$ value and $\delta^{13} \mathrm{C}$ value of riverine POC (b).

\section{ACKNOWLEDGMENTS}

The research described in this paper was funded by a Grant-in-Aid for Scientific Research, No. 18310002 from the Ministry of Education, Science, Sport and Culture in Japan. 


\section{REFERENCES}

Gupta LP, Subramanian V, Ittekkot V. 1997. Biogeochemistry of particulate organic matter transported by the Godavari River, India. Biogeochemistry 38(2):10328.

Hedges JI. 1992. Global biogeochemical cycles: progress and problems. Marine Chemistry 39(1-3):67-93.

Hedges JI, Keil RG, Benner R. 1997. What happens to terrestrial organic matter in the ocean? Organic Geochemistry 27(5-6):195-212.

Ileva N, Shibata Y, Satoh F, Sasa K, Ueda H. 2009. Relationship between the riverine nitrate-nitrogen concentration and the land use in the Teshio River watershed, North Japan. Sustainability Science 4(2): 189-98.

Ittekkot V. 1988. Global trends in the nature of organic matter in river suspensions. Nature 332(6163):436-8.

Japan Meteorological Agency. 2009. Weather, climate and earthquake information [WWW]. http:// www.data.kishou.go.jp/.

Kitagawa H, Masuzawa T, Nakamura T, Matsumoto E. 1993. A batch preparation method of graphite targets with low background for AMS ${ }^{14} \mathrm{C}$ measurements. $R a-$ diocarbon 35(2):295-300.

Koarashi J, Iida T, Asano T. 2005. Radiocarbon and stable carbon isotope compositions of chemically fractionated soil organic matter in a temperate-zone forest, Journal of Environmental Radioactivity 79(2):13756.

Kume H, Shibata Y, Tanaka A, Yoneda M, Kumamoto Y, Uehiro T, Morita M. 1997. The AMS facility at the National Institute for Environmental Studies (NIES), Japan. Nuclear Instrument and Methods in Physics Research B 123(1-4):31-3.

Liu W, Moriizumi J, Yamazawa H, Iida T. 2006. Depth profiles of radiocarbon and carbon isotopic compositions of organic matter and $\mathrm{CO}_{2}$ in a forest soil. Journal of Environmental Radioactivity 90(3):21023.

Masiello CA, Druffel ERM. 2001. Carbon isotope geochemistry of the Santa Clara River. Global Biogeochemical Cycles 15(2):407-16.
Meybeck M. 1982. Carbon, nitrogen, and phosphorous transport by world rivers. American Journal of Science 282:401-50.

Meybeck M. 1993. Riverine transport of atmospheric carbon: sources, global typology, and budget. Water, Air, \& Soil Pollution 70(1-4):443-63.

Milliman JD, Syvitski JPM. 1992. Geomorphic-tectonic control of sediment discharge to the ocean: The importance of small mountainous rivers. Journal of Geology 100(5):525-44.

Ministry of Land, Infrastructure, and Transport. 2009. Water information system [WWW]. http:// www1.river.go.jp/.

Moreira-Turcq P, Seyler P, Guyot JL, Etcheber H. 2003. Exportation of organic carbon from the Amazon River and its main tributaries. Hydrological Processes 17(7):1329-14.

Nagano T, Yanase N, Tsuduki T, Nagao S. 2003. Particulate and dissolved elemental loads in the Kuji River related to discharge rate. Environment International 28(7):649-58.

Nagao S, Usui T, Yamamoto M, Minagawa M, Iwatsuki T, Noda A. 2005. Combined use of $\Delta^{14} \mathrm{C}$ and $\delta^{13} \mathrm{C}$ values to trace transportation and deposition processes of terrestrial particulate organic matter in coastal marine environments. Chemical Geology 218(1-2):63-72.

Paolini J. 1995. Particulate organic carbon and nitrogen in the Orinoco River (Venezuela). Biogeochemistry 29(1):59-70.

Raymond PA, Bauer JE. 2001. Riverine export of aged terrestrial organic matter to the North Atlantic Ocean. Nature 409(6819):497-500.

Stuiver M, Polach HA. 1977. Discussion: reporting of ${ }^{14} \mathrm{C}$ data. Radiocarbon 19(3):355-63.

Trumbore S. 2000. Age of soil organic matter and soil respiration: radiocarbon constraints on belowground C dynamics. Ecological Applications 10(2):399-411.

Trumbore SE, Harden JW. 1997. Accumulation and turnover of carbon in organic and mineral soils of the BOREAS northern study area. Journal of Geophysical Research 102(D24):28,817-30. 